two and five-tenths grams of cyanimidocarbonic ethyl ester, prepared from bromocyanogen, potassium cyanide, and alcohol ${ }^{1}$ were added to the suspended alcoholate. Heat was developed, the solution became yellow, and sodium cyanide was precipitated. The reaction mixture was heated for two hours in a flask connected with a reflux condenser, and enough water was added to dissolve the sodium cyanide. After the water solution had been extracted with ether several times, the ether was dried with calcium chloride. Thus, $32 \mathrm{~g}$. of a light yellow oil, possessing a strong basic odor, were obtained when the ether was evaporated. Even at a pressure of $25 \mathrm{~mm}$. the compound could not be distilled without considerable decomposition. Therefore, no analysis of the substance was attempted. Its identity was established by converting it into the corresponding oximido derivative.

Preparation of Oximidocarbonic Ethyl Isoamyl Ester, $\mathrm{C}_{2} \mathrm{H}_{6} \mathrm{O}-\mathrm{C}-\mathrm{OC}_{5} \mathrm{H}_{11}$ -

Eight and four-tenths grams of hydroxylamine, dissolved in a small amount of water, were added to $20 \mathrm{~g}$. of the imido ester dissolved'in 20 cc. of ether. The mixture was shaken thirty minutes, the water layer was drawn off, extracted several times with ether, and the ether dried with sodium sulfate. Twenty grams of a reddish yellow oil were obtained when the ether evaporated. When cooled to $-15^{\circ}$, white crystals appeared which melted when they were spread out on a cold clay plate.

0.I754 g. gave $12.8 \mathrm{cc}$. $\mathrm{N}_{2}$ at $24.5^{\circ}$ and $742 \mathrm{~mm}$. Calc. for $\mathrm{C}_{8} \mathrm{H}_{17} \mathrm{O}_{3} \mathrm{~N}$ : $\mathrm{N}, 7.99$. Found: $\mathrm{N}, 8.01$.

When freshly prepared, the substance was practically odorless but, on standing, the odor of isoamyl alcohol became apparent. The oil was. insoluble in water, but soluble in alkalies, and in most organic solvents.

Cincranatr, Oнто.

\title{
FRIEDEL AND CRAFTS' REACTION-THE PREPARATION OF ORTHOBENZOYL-BENZOIC ACID AND BENZOPHENONE.
}

By C. R. RuBidge aNd N. C. Qua.

Received February 20, 1914.

Orthobenzoyl-benzoic acid had been prepared by several investigators but was first prepared by means of the reaction between phthalic anhydride, benzene and aluminium chloride, by Friedel and Crafts. ${ }^{2}$ Heller $^{3}$ showed that the aluminium chloride was not a catalytic agent and that a good yield depended on the phthalic anhydride and the aluminium chloride being used in the proportion of their formula weights (using $\mathrm{Al}_{2} \mathrm{Cl}_{6}$ ).

${ }^{1}$ Nef, Loc. cit., p. 293.

2 Ann. chim. phys., [6] 14, 446 (1888).

${ }^{3} Z$. angew. Chem., I9, 669 (I906). 
In a later article Heller and Shülke ${ }^{1}$ suggested that the reaction might be represented as taking place in two stages:

$\mathrm{C}_{8} \mathrm{H}_{4} \mathrm{O}_{3}+\mathrm{C}_{6} \mathrm{H}_{6}+\mathrm{Al}_{2} \mathrm{Cl}_{6} \rightarrow \mathrm{C}_{8} \mathrm{H}_{4} \mathrm{O}_{3} \mathrm{Al}_{2} \mathrm{Cl}_{6} \mathrm{C}_{6} \mathrm{H}_{6} \rightarrow \mathrm{C}_{14} \mathrm{H}_{9} \mathrm{O}_{3} \mathrm{Al}_{2} \mathrm{Cl}_{5}+\mathrm{HCl}$, the latter compound with hydrochloric acid giving orthobenzoyl-benzoic acid. Heller obtained a yield of $93 \%$, or counting in the recovered phthalic acid $97 \%$, and in two experiments obtained $0.87 \mathrm{~mol}$ and $0.93 \mathrm{~mol}$, respectively, of hydrogen chloride for each mol of phthalic anhydride used. Heller also states that if one-half the usual amount of aluminium chloride is used the yield is reduced to less than one-half.

The following experiments on the preparation of orthobenzoyl-benzoic acid and benzophenone, using varying quantities of the reagents, were begun by the first named author and finished by the second.

The aluminium chloride used was Kahlbaum's "sublimed" and had been kept in sealed bottles in the laboratory for more than a year; preliminary experiments showed that this gave as good yields as were obtained when the aluminium chloride had been freshly sublimed. The phthalic anhydride and benzene were obtained from the same firm but it was found better to resublime the phthalic anhydride.

The apparatus consisted of a flask which was connected with a reflux condenser and had also an inlet for dry air; the condenser was connected with a $U$-tube containing calcium chloride and then with two Liebig bulbs containing potassium hydroxide solution. Dry air could thus be drawn through the apparatus, and the hydrogen chloride given off determined. Five grams of phthalic anhydride and $18-20 \mathrm{cc}$. benzene were placed in the flask and heated until the anhydride was dissolved, after cooling, $9 \mathrm{~g}$. aluminium chloride were added gradually; this was allowed to stand at room temperature for one hour, in order that the hydrogen chloride should not be given off so rapidly as to prevent complete absorption in the Liebig bulbs, and then the flask was heated on the water bath and kept boiling for two hours. Ioo cc. of dilute hydrochloric acid (20 cc. conc. hydrochloric acid to $80 \mathrm{cc}$. water) were added to the cooled contents of the flask, the benzene distilled off with steam, the residue cooled to $0^{\circ}$, and the orthobenzoyl-benzoic acid filtered off; this was washed with cold water, redissolved in sodium carbonate and precipitated with hydrochloric acid. In this way we obtained a $96-97 \%$ yield with no phthalic acid and never more than a trace of diphenylphthalide.

When less aluminium chloride was used both phthalic acid and diphenylphthalide were obtained. The diphenylphthalide was separated by its insolubility in sodium carbonate solution and the remaining acids were separated by extracting the benzoyl-benzoic acid from the phthalic acid by chloroform. Small quantities of the two acids were also recovered from the first filtrate containing the aluminium chloride.

${ }^{1}$ Ber., 4I, 3627 (I908). 
In the following table the phthalic acid recovered has been omitted and the hydrogen chloride has been expressed in formula weights per formula weight of aluminium chloride used $\left(\mathrm{Al}_{2} \mathrm{Cl}_{6}\right)$ :

\begin{tabular}{|c|c|c|c|c|c|c|c|c|c|}
\hline No. & $\begin{array}{c}\text { Benzene } \\
\text { Cc. }\end{array}$ & $\begin{array}{c}\text { Ph. } \\
\text { anhy } \\
\text { Gram }\end{array}$ & & $\begin{array}{l}\text { Al. chl. } \\
\text { Grams. }\end{array}$ & & $\begin{array}{l}\text { Time } \\
\text { boiled. } \\
\text { Hours. }\end{array}$ & $\begin{array}{l}\text { Benzoyl } \\
\text { benz. ac } \\
\text { Grams. }\end{array}$ & $\begin{array}{l}\text { Diphen. } \\
\text { phth. } \\
\text { Grams. }\end{array}$ & $\begin{array}{l}\text { Hydr } \\
\text { chl. }\end{array}$ \\
\hline$x \ldots \ldots \ldots \ldots \ldots \ldots$ & 18 & 5 & & 9 & & 2 & $7 \cdot 36$ & None & 1.17 \\
\hline $2 \ldots \ldots \ldots \ldots \ldots \ldots$ & . $\quad 18$ & 5 & & 9 & & 2 & 7.29 & None & 1.18 \\
\hline $3 \ldots \ldots \ldots \ldots \ldots \ldots$ & . $\quad 18$ & 5 & & 9 & & 2 & 7.39 & None & 1.17 \\
\hline $4, \ldots \ldots \ldots, \ldots \ldots$ & - 18 & 5 & & $4 \cdot 5$ & & 2 & 2.03 & 0.45 & 1.02 \\
\hline $5 \ldots \ldots \ldots \ldots \ldots$ & - I 8 & 5 & & $4 \cdot 5$ & & 2 & 2.01 & 0 & $0.9 \mathrm{I}$ \\
\hline $6 \ldots \ldots \ldots \ldots \ldots$ & . 18 & 5 & & $4 \cdot 5$ & & 2 & 2.47 & 0.86 & $\mathrm{r} .09$ \\
\hline $7 \ldots \ldots \ldots \ldots \ldots \ldots$ & . 18 & 5 & & $4 \cdot 5$ & & 0.5 & 2.87 & 0.17 & 0.90 \\
\hline $8 \ldots \ldots \ldots \ldots \ldots \ldots$ & . 20 & 5 & & $4 \cdot 5$ & & $3 \cdot 5$ & . & I. 17 & 1.27 \\
\hline $9 \ldots \ldots \ldots \ldots \ldots$ & . 20 & 5 & & $4 \cdot 5$ & & 8.5 & . & 1.36 & I. 25 \\
\hline 10 $\ldots \ldots \ldots \ldots \ldots$ & - 36 & $5+$ & 5 & 9 & 2 & +2 & 5.14 & 0.88 & I. 20 \\
\hline I $\ldots \ldots \ldots \ldots \ldots \ldots$ & 40 & $5+$ & 5 & 9 & 2 & +2 & 6.72 & 0.96 & I. 02 \\
\hline $12 \ldots \ldots \ldots \ldots \ldots \ldots$ & . 40 & $5+$ & 2 & 9 & 2 & +2 & $7 \cdot 5 \mathrm{I}$ & 0.30 & 1.24 \\
\hline $13 \ldots \ldots \ldots \ldots \ldots \ldots$ & 30 & 5 & & 18 & & 2 & 7.23 & None & . \\
\hline$r_{4} \ldots \ldots \ldots \ldots \ldots \ldots$ & . 20 & 5 & $4 \cdot 5$ & $5+4 \cdot 5$ & 2 & +2 & $6.5^{\circ}$ & 0.65 & 1.31 \\
\hline${ }_{15} \ldots \ldots \ldots \ldots \ldots \ldots \ldots$ & 20 & 5 & & 2.3 & & 2 & 0.78 & 0.6 & $\mathrm{I} . \infty$ \\
\hline
\end{tabular}

From Nos. $1-3$ it will be seen that, using the proportions of the reagents indicated, the yield of orthobenzoyl-benzoic acid is practically constant and the hydrogen chloride given off is nearly $\mathrm{I}, 2$ formula weights per formula weight of aluminium chloride used. There is no diphenylphthalide formed. In Nos. 4-6, using half the amount of aluminium chloride, the yield of orthobenzoyl-benzoic acid is less than one-third and not so constant and diphenylphthalide is found. Nos. 7-9 show that longer boiling materially increases the yield of diphenylphthalide. In Nos. IO-I 2 the usual proportions of the reagents were used and after two hours' boiling, additional phthalic anhydride was added and boiling continued for two hours. It is known from Nos. I-3 that these preparations would have yielded no diphenylphthalide at the end of the first two hours' boiling and would have given a $97 \%$ yield of orthobenzoyl-benzoic acid, so that the diphenylphthalide obtained must have been due to the action of the additional phthalic anhydride on the intermediate compound. No. ${ }_{3}$ shows that increasing the amount of aluminium chloride produces no diphenylphthalide, No. 14 that beginning with a small amount of the aluminium chloride and increasing it during the course of the reaction does not prevent the formation of diphenylphthalide, and in No. I5 only one-quarter of the usual amount of aluminium chloride was used and the yield of orthobenzoyl-benzoic acid was very small.

Since the diphenylphthalide is shown to be produced by the action of the phthalic anhydride on the intermediate product which would have given orthobenzoyl-benzoic acid, experiments were made to see whether other acid anhydrides would have a similar effect. 
Expt. I6.-Twenty grams of phthalic anhydride, $80 \mathrm{cc}$. benzene and 18 g. aluminium chloride, boiled for two hours, then $13.6 \mathrm{~g}$. succinic anhydride added and boiling continued for two hours, gave II $\mathrm{g}$. diphenylphthalide and not more than a trace of orthobenzoylbenzoic acid.

Expt. 17.-Fourteen and eight-tenths grams of phthalic anhydride, $80 \mathrm{cc}$. benzene and $13.3 \mathrm{~g}$. aluminium chloride, boiled for two hours, then I0.2 g. acetic anhydride added and boiling continued for two hours, gave $8.8 \mathrm{~g}$. diphenylphthalide and no orthobenzoyl-benzoic acid.

Von Pechmann ${ }^{1}$ found that in the preparation of orthobenzoyl-benzoic acid some diphenylphthalide was found and he also states that diphenylphthalide may be prepared from orthobenzoyl-benzoic acid, aluminium chloride and benzene, but that a better yield was obtained from the mixed anhydride of orthobenzoyl-benzoic and acetic acids.

Expt. 18.-Seven and four-tenths grams of orthobenzoyl-benzoic acid, $20 \mathrm{cc}$. benzene and $9 \mathrm{~g}$. aluminium chloride were boiled for two hours and gave $0.1 \mathrm{~g}$. diphenylphthalide. This experiment may be compared with Experiment 13 , in which an excess of aluminium chloride was used and there must have been present the intermediate compound and aluminium chloride, so that although orthobenzoyl-benzoic acid with aluminium chloride will give a small quantity of diphenylphthalide the intermediate compound with aluminium chloride will give none unless an acid anhydride is present.

Experiments were also made, along the same line, in the preparation of benzophenone from benzoyl chloride, benzene and aluminium chloride. The benzoyl chloride was dissolved in benzene and powdered aluminium chloride added. It is not necessary to add the aluminium chloride gradually when a large excess of benzene is used. The flask was heated very gently on the water-bath for 20-30 minutes and when the evolution of hydrogen chloride became slower the temperature was raised to boiling. Three and one-half hours' boiling was found to give the maximum yield of benzophenone, but the yield of hydrogen chloride was so variable that records are not given. The contents of the flask were poured into 200 cc. of cold water, Io $\mathrm{cc}$. of conc. hydrochloric acid added and the benzene distilled off with steam. The benzophenone was then extracted with ether, the benzoic acid extracted from the ethereal solution with $10 \%$ sodium hydroxide solution and the benzophenone obtained by evaporation of the ether. The benzophenone so obtained was pink in color but was not further purified, as distillation would have involved a considerable and variable loss. Small quantities of benzophenone were also recovered from the distillate containing the benzene.

Expt. I 9 (in duplicate). - Twelve and one-tenth grams of benzoyl chloride, I Ber., 14, 1865 (188I). 
I $30 \mathrm{cc}$. benzene and $12.1 \mathrm{~g}$. aluminium chloride gave benzophenone: 12.8 g.; $12.8 \mathrm{~g}$.

Expt. 20 (in duplicate).-Twelve and one-tenth grams of benzoyl chloride, I $30 \mathrm{cc}$. benzene and $6.06 \mathrm{~g}$. aluminium chloride gave benzophenone: $5.8 \mathrm{~g} . ; 5.8 \mathrm{~g}$.

Experiments $I_{9}$ and 20 show that reducing the aluminium chloride to one-half reduces the yield of benzophenone to a little less than one-half. No other product was obtained except benzoic acid.

Expt. 2 I (in duplicate).-Twelve and one-tenth grams of benzoyl chloride, I $30 \mathrm{cc}$. benzene and I2. I g. aluminium chloride, boiled for three and onehalf hours, then $8.75 \mathrm{~g}$. phthalyl chloride added and boiling continued for three and one-half hours gave benzophenone: II. 2 g.; I 2 . I g.; and diphenylphthalide: 5.1 g.; 4.8 g. This experiment shows that the addition of phthalyl chloride at the end of the preparation for benzophenone gave diphenylphthalide, without materially reducing the yield of benzophenone.

Expt. 22 (in duplicate).-Eight and three-quarters grams of phthalyl chloride, I $30 \mathrm{cc}$. benzene and $6.5 \mathrm{~g}$. aluminium chloride gave diphenylphthalide: $10.0 \mathrm{~g}$; io. $0 \mathrm{~g}$.

Expt. 23.-Eight and three-quarters grams of phthalyl chloride, I30 cc. benzene and $6.5 \mathrm{~g}$. aluminium chloride boiled for three and one-half hours, then I2. I $\mathrm{g}$. benzoyl chloride added and boiling continued for three and one-half hours gave diphenylphthalide (not weighed) but no benzophenone.

Expt. 24.-Ten grams of phthalic anhydride, Ioo cc. benzene and I2. I g. aluminium chloride boiled for two hours, then $\mathrm{I} 4 \mathrm{~g}$. phthalyl chloride added and boiling continued for two hours gave diphenylphthalide: I 4 g., and no orthobenzoyl-benzoic acid. This shows' that phthalyl chloride, added at the end of the preparation for orthobenzoyl-benzoic acid, acts on the intermediate compound in the same way as the acid anhydrides and gives a much better yield of diphenylphthalide.

Expt. 25.-Fourteen grams of phthaly1 chloride, $100 \mathrm{cc}$. benzene and I2. I g. aluminium chloride boiled for two hours, then ro g. phthalic anhydride added and boiling continued for two hours gave diphenylphthalide: $19.6 \mathrm{~g}$. In this experiment the addition of phthalic anhydride has somewhat increased the yield of diphenylphthalide (compare Experiment 22).

Expt. 26.-Fourteen and eight-tenths grams of benzoic anhydride, $\mathrm{r} 50 \mathrm{cc}$. benzene and $20.5 \mathrm{~g}$. aluminium chloride boiled for two hours gave $6.3 \mathrm{~g}$. of benzophenone.

Expt. 27.-Eight and three-tenths grams of phthalic anhydride, roo cc. benzene and $\mathrm{I} 5 \mathrm{~g}$. aluminium chloride boiled for two hours, then $12.7 \mathrm{~g}$. benzoic anhydride added and boiling continued for two hours, gave $6 \mathrm{~g}$. of benzophenone, and diphenylphthalide and orthobenzoyl-benzoic acid 
(not weighed). In this experiment it is seen that the benzoic anhydride has the same effect as the other acid anhydrides but gives a considerable yield of benzophenone as well.

\section{Summary.}

I. Friedel and Crafts' method of preparing orthobenzoyl-benzoic acid, as used by Heller, was found to give a $97 \%$ yield and nearly I . 2 formula weights of hydrogen chloride for each formula weight of aluminium chloride used $\left(\mathrm{Al}_{2} \mathrm{Cl}_{6}\right)$.

2. When less aluminium chloride is used the yield of orthobenzoylbenzoic acid is very much reduced and diphenylphthalide is obtained, and this is found to be due to the action of the phthalic anhydride on the intermediate compound.

3. Succinic anhydride, acetic anhydride, benzoic anhydride and phthalyl chloride also give diphenylphthalide with this intermediate compound.

4. In the preparation of benzophenone from benzoyl chloride, benzene and aluminium chloride, reducing the amount of aluminium chloride reduces the yield almost in the same proportion and the addition of phthalyl chloride gives diphenylphthalide, without materially reducing the yield of benzophenone.

5. Benzophenone may be obtained from benzoic anhydride, benzene and aluminium chloride, but the yield is not good.

6. In the case of the addition of benzoic anhydride to the preparation for orthobenzoyl-benzoic acid, benzophenone is produced in addition to diphenylphthalide.

These experiments were carried out under the direction of F. B. Allan. UNIVERSITY OF TORONTO.

\section{SOME PHYSICAL PROPERTIES OF ETHANE, ETHYLENE AND ACETYLENE. \\ By O. MaAss and D. McIntosh. \\ Received February 21, 1914.}

In the course of an investigation on the physical properties of bodies at low temperatures, we have found it necessary to measure some of the constants of ethane, ethylene and acetylene, which are not given in the chemical literature. A comparison of these three bodies, each containing two carbon atoms, but with different linkages, is not without interest, while a publication of the results may save labor on the part of some chemists. We give them here, therefore, together with a description of the methods employed in their determination.

Ethane.-The ethane was made from methyl iodide, by the action of the zinc-copper couple. It was washed with alkali, dried by phosphorus pentoxide, passed through three spirals cooled to $-78^{\circ}$, twice distilled, the middle portions being retaited, and was finally introduced 